\title{
Corantes comumente empregados na citogenética vegetal
}

\author{
Dyes usually employed in plant cytogenetics
}

\author{
Sandra Patussi Brammer ${ }^{1 *}$, Claudia Toniazzo², Liane Balvedi Poersch ${ }^{3}$
}

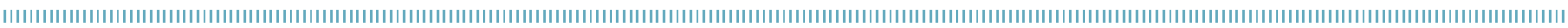

RESUMO: O emprego dos corantes, na citogenética vegetal, data de muitos anos, uma vez que as pesquisas nas áreas da citologia e histologia vêm sendo desenvolvidas constantemente desde os primeiros estudos celulares no século XIX. Inicialmente, eram extraídos de fontes vegetais ou animais, sendo atualmente produzidos sinteticamente em escala comercial. Os corantes são classificados em não fluorescentes e fluorescentes, conforme suas propriedades químicas e a escolha de uso é de acordo com o tipo de estrutura celular ou grupo celular a ser analisado. A diversidade de tipos e compostos químicos existentes nos diferentes corantes proporciona sua aplicaçáo em estudos avançados na citogenética clássica e molecular. Uma revisão de suas propriedades químicas e emprego é apresentada para os corantes não fluorescentes orceína, hematoxilina, Giemsa, carmin; e para os fluorescentes 4',6-diamidino-2-fenilindol (DAPI), cromomicina A (CMA), fluoresceína e rodamina.

PALAVRAS-CHAVE: biologia celular; citologia; histologia; compostos químicos.

\begin{abstract}
The use of dyes in plant cytogenetics goes back many years, as research in the fields of cytology and histology has been constantly developed since the first cellular studies in the $19^{\text {th }}$ century. Initially they were taken from plant or animal sources, and now they are produced synthetically on a commercial scale. These dyes are classified in fluorescent and non-fluorescent, according to their chemical properties and the choice of use is based on the type of cell structure or cell group to be analyzed. The diversity of types and chemical compounds available in different dyes provides their application in advanced and classical cytogenetics studies. A review of their chemical properties and use is presented for the non-fluorescent dyes orcein, hematoxylin, Giemsa, and carmine; and for the fluorescent dyes 4',6-diamidino-2-phenylindole (DAPI), chromomycin A (CMA), fluorescein, and rhodamine.
\end{abstract}

KEYWORDS: cell biology; cytology; histology; chemical compounds. 
Corantes são compostos químicos, naturais ou sintéticos, que se fixam em escala molecular a um substrato. Quando empregados nas áreas biológicas permitem evidenciar os vacúolos, núcleos, nucléolos, membranas celulares, algumas organelas citoplasmáticas, entre outras estruturas. Seu emprego data de centenas de anos, sendo que até o período anterior à metade do século XIX, os corantes eram quase sempre isolados de fontes naturais, principalmente oriundas de vegetais ou animais.

Os corantes e pigmentos podem ser classificados de acordo com as classes químicas às quais pertencem e com as aplicaçóes a que se destinam. O Colour Index (CI) contém uma lista organizada de nomes e números para designar os diversos corantes produzidos sinteticamente com propriedades superiores tecnicamente. O emprego e a escolha dos diferentes corantes, tanto em citogenética clássica como molecular, é de extrema importância, uma vez que permitem corar regióes distintas das células, bem como diferentes grupos celulares para posterior identificação no microscópio. Neste sentido, propõe-se uma breve revisão de alguns dos corantes comumente usados em citogenética vegetal, procurando também destacar aspectos históricos, suas propriedades químicas, bem como sua eficácia nas análises citológicas.

A orceína é um corante alimentar natural, com número de registro EE121 (código referente a suplementos alimentícios com uso na Uniáo Europeia) e 1400-62-0 no Chemical Abstracts Service (CAS). Possui propriedades básicas e apresenta-se homocromática.

O líquen do qual se extrai a orceína pertence à família Roccellaceae, é denominado Roccella tinctoria e produz uma tintura vermelho-violáceo. A localização geográfica desse líquen foi muito ampliada desde aquela época. $\mathrm{O} R$. tinctoria foi extensivamente explorado nos meados do século $\mathrm{XV}$ até a década de 1850 por sua coloração ser de grande valor para o setor têxtil, uma vez que antes da invençáo das anilinas sintéticas, essa era uma das poucas formas de se obter a cor púrpura e tingir tecidos sem a necessidade de usar mordentes (Troconís, 2000). Constituiu uma importante fonte econômica para o setor têxtil, principalmente no século XVI, quando as substâncias que compóem os corantes eram obtidas de diferentes órgãos vegetais por meio de processos físico-químicos. As cores resultantes eram classificadas em dois grupos econômicos, de acordo com a dificuldade de obtenção: as muito caras (púrpura, azul e tons de vermelho), e as menos dispendiosas (verde, cor-de-rosa, cor de laranja, cinza e amarelo). A orceína era usada para tingir lá e seda em tons de vermelho, castanho e azulado (FARIA, 1991).

Do ponto de vista químico, esse corante começou a ser pesquisado em 1829 pelo francês Pierre Jean Robiquet (17801840), que fazia sua extração com etanol. No século XX, a orceína foi melhor estudada pelo também químico Hans Musso (1925-1988), o qual elucidou seus componentes químicos e passou a fazer a extraçáo do corante por uma reação de amônia e ar, muito próxima da técnica usada atualmente. Por seus estudos com o líquen e a orceína em si, publicou em torno de 25 documentos entre 1956 e 1965, catalogando assim sua fórmula química $\left(\mathrm{C}_{28} \mathrm{H}_{2} \mathrm{~N}_{2} \mathrm{O}_{7}\right)$, dentre outras substâncias como as orceínas, amino-orceínas e amino-orceiniminas.

A orceína geralmente é usada associada ao ácido acético e, nessa combinação, possui ampla aplicação como contraste em microscopia como base para indicadores químicos e bioquímicos. Essa solução, por apresentar um baixo $\mathrm{pH}$, torna mais específica a coloração, tendo em vista que os ácidos nucleicos são as biomoléculas com o menor ponto isoelétrico da célula (Coutinho, 2008).

Atualmente, sua produçáo é feita em larga escala a partir do orcinol, por meio da oxidação com peróxido de hidrogênio, presente na amônia. Essa técnica foi desenvolvida pelo escocês Gordon Cuthbert, tendo sua produção iniciada e patenteada em 1758, pela British patente. A reação de extração do corante dura seis semanas. Os líquens são postos em soluçôes de amoníaco (antigamente a urina era usada como fonte) por dois dias, após, essa soluçáo é misturada com cal apagada para fermentar pelo resto do tempo do processo, quando ao final se obterá a orceína.

Lacour, em 1941, encontrou um novo uso para a orceína, a técnica da acetato-orceína, para fixar e colorir os cromossomos, podendo assim estudar seu número, forma e deformidades. Essa técnica é usada na citogenética animal e vegetal, existindo, em alguns casos, uma preferência pelo corante natural ao sintético (Troconís, 2000).

A hematoxilina propriamente dita não é um corante, mas sim um composto fenólico obtido da espécie Haematoxylum campechianum, também conhecia pelo nome "pau campeche", pertencente à família Leguminosae. É de origem natural, e quando em contato com oxigênio é oxidada e resulta em uma substância de cor marrom-avermelhado escura denominada hemateína. Sua cor de cadastro é preto natural 1 (Natural Black 1), classificada pelo CI 75290, número CAS 517-28-2 e fórmula molecular $\mathrm{C}_{16} \mathrm{H}_{14} \mathrm{O}_{6}$. A descoberta de sais de metais pesados que podem ser usados como mordentes com a hematoxilina forneceu uma grande vantagem aos histologistas, pois o uso de sais de ferro confere coloração cinza a preta, os sais de cobre, uma coloração azulada, e os sais de cromo, uma coloraçâo violeta a acinzentada (Titford, 2005). Por exemplo, o uso de alumínio resulta na cor azul, potássio na cor roxa/violeta, ferro na cor preta e cobre na cor verde (GILL, 2010). Seu emprego data do século XIX, sendo inicialmente usado para histologia por volta do ano de 1830 (Von WaLdeYer, 1863 apud Titford, 2005), quando o primeiro uso eficaz da hematoxilina foi registrado, em 1865 por Böhmer, em 1865. Desde então, apareceram diversas formulaçóes, entre as mais populares as de Harris, Gill, Mayer e Weigert (Sigma-Aldrich, 2003).

A molécula de hemateína não é muito eficiente na coloração propriamente dita, por possuir carga negativa, dificultando, desse modo, a ligação com o DNA e as nucleoproteínas (cromatina). O que realmente cora essas biomoléculas é a 
adição dos mordentes positivamente carregados (GILL, 2010). A hematoxilina é um composto básico que carrega uma carga positiva na porção da molécula que confere cor ao tecido, geralmente azul. Soluçóes básicas reagem com os componentes aniônicos das células e tecidos, os quais incluem grupos fosfatos, ácidos nucleicos, grupos sulfatos de glicosaminoglicanas e grupos carboxila das proteínas. A habilidade de grupos aniônicos reagirem com corantes básicos é chamada basofilia. Estruturas celulares que podem ser coradas com corantes básicos incluem: heterocromatina, nucléolo, RNA ribossômico e matriz extracelular da cartilagem.

A hematoxilina é muito utilizada em laboratórios de histologia nos procedimentos de coloraçáo biológica, geralmente corando em azul quando associada a um sal metálico como mordente e tornando-se de cor violeta em $\mathrm{pHs}$ mais ácidos (Titrord, 2005). Atua intensamente nos núcleos das células, uma vez que contém ácidos nucleicos ricos em radicais ácidos. A coloração histológica pela hematoxilina não indica a constituição química dos componentes celulares, mas a densidade de cargas elétricas negativas dos mesmos. Tem a finalidade de destacar estruturas nucleares e citoplasmáticas, formando lacas ou complexos coloridos (complexos corante-mordente-tecido). A hematoxilina de Ehrlich e a hematoxilina de Harris são as duas principais soluçóes de hematoxilina utilizadas em coloração histológica. $\mathrm{O}$ alúmen confere ao núcleo uma coloração azul transparente luminosa que rapidamente se torna vermelha na presença de um ácido (Guerra, 1999).

Misturas de hematoxilina e alúmen férrico, combinadas com uma hidrólise clorídrica forte, também são utilizadas na observação de cromossomos de diversos tipos de vegetais e alguns animais, sempre fornecendo bons resultados. No caso das células vegetais, o aspecto técnico mais importante é o uso da hidrólise clorídrica, pelo fato do citoplasma ser muito transparente e se combinar com a coloraçáo intensa e específica produzida pela hematoxilina. Além disso, devido ao maior contraste obtido entre citoplasma e cromatina, ela se mostra muito útil para uma coloraçấo sequencial de células previamente analisadas com outros corantes e para materiais com problemas de fixação. Desse modo, a hidrólise clorídrica suaviza muito a parede da célula, permitindo uma melhor visualização de células e cromossomos (FujiI; Guerra, 1998). Por outro lado, ela muitas vezes impede a observação do nucléolo. Quando o nucléolo deve ser observado, a etapa de hidrólise deve ser provisoriamente suprimida ou reduzida ao menor tempo possível (Henderson; Lu, 1968). Contudo, o nucléolo frequentemente fica bem corado em alguns tecidos vegetais que foram fixados à temperatura de $20^{\circ} \mathrm{C}$ ou superiores, mesmo após 20 minutos de hidrólise clorídrica (Guerra, 1999). A cromatina, quando corada com hematoxilina, pode não apresentar resultados satisfatórios na presença de vestígios de ácido clorídrico $(\mathrm{HCl})$. Contudo, se for realizada cuidadosa lavagem dos tecidos após a hidrólise, esse problema pode ser reduzido ou evitado, garantindo a transparência do citoplasma (WitTmann, 1965).

Quando a análise é realizada em botôes florais, eles devem ser hidrolisados por um tempo muito curto para evitar amaciamento excessivo, o que, muitas vezes, dificulta a dissecação da antera para a liberação dos micrósporos e grãos de pólen. Nesse caso, os cromossomos, quando visualizados na mitose do pólen, podem ser claramente detectados, já que o corante náo reage com a exina da célula, além de permitir um bom contraste entre citoplasma e cromatina corada com hematoxilina (Guerra, 1999). Entretanto, Kindiger; Beckett (1985) apud FujIi; Guerra (1998) sugeriram apenas o aquecimento da lâmina para reduzir o escurecimento do citoplasma dos grãos de pólen corados com hematoxilina $2 \%$. Esse método reduz a coloração do citoplasma, embora o contraste final continue deficiente, quando comparado com o grão de pólen hidrolizado.

A hematoxilina permite também o contraste resultante de sua coloração entre núcleo e citoplasma. Por exemplo, essa substância cora a cromatina, especialmente em interfase, com uma maior intensidade quando comparada a outros corantes em tecidos de algas e briófitas (FujiI; Guerra, 1998). Outro exemplo constitui melhores resultados obtidos com esse corante em amostras com tendência de coloração escura do citoplasma (amostras fixadas e armazenadas por dez anos ou mais ou amostras de campo fixadas e estocadas em temperaturas desapropriadas) (GUERRA, 1999). Ross et al. (1996) apud FuJjI; GuerRa (1998), usando uma solução de coloração semelhante, descobriram que reduzindo o tempo de hidrólise foi possível corar não só o nucléolo, mas também a heterocromatina pericentromérica de bivalentes de Arabidopsis. No entanto, coloraçóes convencionais, por vezes, podem produzir falsos padrôes de heterocromatina, sendo possível distinguir eucromatina condensada de heterocromatina, uma vez que a heterocromatina geralmente é melhor diferenciada por bandas $\mathrm{C}$ no procedimento com Giemsa do que por qualquer outro método (GUERRA, 1988).

Essa coloração de Giemsa é classificada como policromática, pois consiste em uma mistura de compostos que originam diferenças sutis na coloração (SAXENA, 2010). É um composto neutro dos corantes azur II (mistura não oxidada de azur I e azul de metileno) e eosinato de azur II (corante formado pela combinaçáo equimolar de azur I, azul de metileno e eosina amarelada). Azur I era o nome usado para azure B (KLERNAN, 2010). É empregada para demonstração dos corpos de Negri, espiroquetas, protozoários, coloração diferencial de esfregaços sanguíneos e para cromossomos (CRUZ, 2009; Brown, 2010).

Vários pesquisadores contribuíram na busca de uma coloração equilibrada à técnica de revelação por Giemsa, destacando Jenner, Grunwald, Leishman e Wright. Contudo, foi Gustav Giemsa (1867-1948), farmacêutico, químico e bacteriologista, que identificou, tendo como base o corante azul 
B, uma forma de melhorar e controlar a oxidaçáo do corante. Ele foi combinado com eosina em metanol e mistura de glicerol, criando assim uma solução estável, com resultados reprodutíveis. Seu artigo foi publicado em 1904, e sua formulação ainda é usada atualmente (FleisCher, 2004).

A coloração de Giemsa é comumente usada em citogenética vegetal, mais precisamente na identificação de bandas G (campo claro) para observação de cromossomos em metáfase, possibilitando assim a análise de repetiçôes e genes não funcionais. A coloração de Giemsa teve também papel fundamental em citogenética molecular, tendo em vista que o descobrimento das técnicas de bandeamento cromossômico possibilitou essa abordagem de estudo, sendo amplamente aplicada, atualmente, na detecção de bandas cromossômicas por fluorocromos.

Ressaltam-se que as técnicas de bandeamento aumentaram muito as possibilidades de pesquisa em citogenética, uma vez que, no pareamento cromossômico e montagem de cariótipos, cada par cromossômico apresenta um padrão distinto e bem característico de bandas. Contudo, a variação no método de Giemsa produz padrôes de bandas que são o reverso das bandas $\mathrm{G}$, isso é, as bandas $\mathrm{G}$ escuras são as bandas $\mathrm{R}$ claras e vice-versa (Brammer et al., 2007). Além disso, conforme Guerra (1988), é possível localizar exatamente a região do cromossomo diretamente afetada, o que seria impossível com a coloraçấo convencional. Semelhante a outras espécies, essas técnicas têm possibilitado compreender melhor as alteraçôes cromossômicas que se estabeleceram em cada cariótipo.

No caso do carmim, o composto que origina esse corante constitui-se no ácido carmínico, o qual vem da cochonilha (EXBRAYT, 2001; DAPSON, 2007). Os primeiros usuários desse corante foram Astecas, Maias e Incas, embora devido à sua longa história, muita confusão e incertezas estâo presentes sobre sua origem, extração, uso e composição. Há grande ambiguidade sobre os nomes desse corante, pela falta de conhecimento concreto sobre sua composição e processo de fabricação. Muitos fornecedores se resguardam e não descrevem exatamente o produto, discernindo entre cochonilha (material bruto resultante do corpo de fêmeas de Dactylopius coccus), carmim (complexo conjugado com metal envolvendo o ácido carmínico e o alumínio), ácido carmínico (ingrediente de cor ativa da cochonilha que ocasionalmente aparece no mercado científico) e ácido aminocarmínico (derivado do ácido carmínico reagido com amônia) (DAPSON, 2007).

A variação da qualidade do corante é um sério problema no uso científico, sendo que algumas das causas são diferenças climáticas, de solo, de estaçáo e geográficas (MeNDEZ et al., 2004). Outro fator que influencia a qualidade do corante constitui-se no fato de que as fêmeas de cochonilha possuem um corante mais puro do que machos e tipos selvagens, e cochonilha premium contém apenas fêmeas grávidas (DAPSON, 2007).

Para fins científicos, o ácido carmínico pode ser purificado, mas esse é um processo caro e raramente usado para fazer o corante, sendo utilizado o carmim (derivado do ácido carmínico com alumínio), proveniente de um composto de extrato de cochonilha com hidróxido de alumínio. Por meio de análises espectrofotométricas, torna-se possível a identificação dos três diferentes corantes (carmim, ácido carmínico e ácido aminocarmínico).

Amostras que não passam pela certificação frequentemente têm seu nome no rótulo trocado de carmim para ácido carmínico e vice-versa. Ressalta-se que o ácido carmínico apresenta a fórmula molecular $\mathrm{C}_{22} \mathrm{H}_{19} \mathrm{O}_{13}$ e seu peso molecular é 941 . Algumas fórmulas estruturais do carmim apresentam um íon cálcio, mas ele provavelmente provém do processo de extraçáo e náo faz parte essencial do carmim. Cada molécula de carmim possui 18 sítios capazes de formar pontes de hidrogênio (DApson, 2007).

Por outro lado, considerando os corantes utilizados nas técnicas de citogenética molecular, as biomoléculas podem ser marcadas com sondas fluorescentes para que possam ser realizados inúmeros testes in vitro. Para que uma molécula seja fluorescente, ela deve ter a capacidade de absorver fótons de energia (excitação) em um determinado comprimento de onda e emitir energia (emissão) em outro comprimento de onda. A excitaçáo e a emissáo náo ocorrem apenas em determinado comprimento de onda, mas sim em uma faixa (podendo ser estreita ou não) onde há um pico máximo considerado (LAKOwICZ, 2006; Hermanson, 2008). Geralmente esses comprimentos de onda estâo na faixa do espectro de luz ultra violeta (UV). A seguir, são apresentados alguns fluorocromos usados em análises citogenéticas de plantas.

O DAPI (4',6-diamidino-2-fenilindol) é um corante fluorescente que emite a cor azul brilhante. Devido à afinidade pelo material genético gerar pouco background citoplasmático, é utilizado como contracorante nuclear clássico na microscopia de fluorescência (Thermo Scientific, 2009). Quando está ligado ao DNA nuclear, sua fluorescência se intensifica 20 vezes (Coleman et al., 1981) e fluoresce devido à inibiçấo na rotação interna em sua estrutura molecular (KAPUSCINSKI; YANAGI, 1979).

O DAPI também se liga e cora o RNA, porém de uma maneira diferente. Nesse complexo, ele possui um comprimento de onda de emissão máxima de aproximadamente $500 \mathrm{~nm}$ (e não 460 como quando ligado ao DNA). Por essa razão, a presença de RNA não interfere na observação nuclear. Seu peso molecular fica em 350,3. A liberação de sua fluorescência necessita de uma excitaçáo máxima perto da faixa de luz UV de 345 a 358 nm e de uma emissão máxima de 455 a $461 \mathrm{~nm}$ (Invitrogen, 2006; Thermo Scientific, 2009). Entretanto, como a associaçấo é muito mais forte no polímero de DNA (100 vezes maior) do que de RNA, o composto se dissocia muito mais lentamente no primeiro caso (TANious et al., 1992). SHu et al. (2001) observaram que o DAPI possui forte afinidade ao poli[d(A-T)] e se mostra apagado quando ligado ao poli $[\mathrm{d}(\mathrm{G}-\mathrm{C})]$. 
É estável quando estocado a $-20^{\circ} \mathrm{C}$, sendo recomendado para uso em longo prazo. Em curto prazo, a solução de coloraçáo pode ser estocada entre 2 e $6^{\circ} \mathrm{C}$, e se manuseada adequadamente, permanece estável por cerca de três anos e por até três meses, respectivamente, porém em ambos os casos deve ser sempre protegida da luz. Possui propriedades mutagênicas e por isso deve ser manuseado com muito cuidado e segurança, podendo ser removido de soluçôes aquosas por meio de carváo ativado (Invitrogen, 2006; Sigma-Aldrich, 2008).

Esse fluorocromo é usado para o estudo de cromossomos e de cromatina, tanto de plantas como de animais, e pode ser aplicado na citometria de fluxo, coloraçáo de cromossomos, visualização e quantificação de DNA, técnicas de coloração de anticorpos, hibridização in situ, ensaio fluorescente de DNA em solução e visualizaçáo de DNA em gel de eletroforese.

Técnicas recentes empregadas em estudos citogenéticos têm possibilitado uma análise mais detalhada dos cariótipos a partir de dados citomoleculares, como por exemplo os bandeamentos com DAPI, uma vez que ele destaca regióes heterocromáticas ricas em bases adenosina e timina (AT) (Coelho, 2009).

A utilização do DAPI como corante para a citometria de fluxo foi proposta, segundo Отто (1994), pelos pesquisadores Göhde, Schumann e Zante no ano de 1978 e, desde entáo, ele vem sendo empregado por vários autores, demonstrando sua eficácia. Em função do corante apresentar predileção pelas regióes ricas em AT, a posição dos picos não fornece uma informaçấo quantitativa do conteúdo de DNA de células de diferentes espécies. Contudo, os picos de referência obtidos das células padrão permitem variaçôes no conteúdo de DNA, e o coeficiente de variação num dado tipo de célula pode ser detectado (Отто, 1994). Pode ser usado também na microfluorometria de fluxo (TAYLOR, 1980). Essa técnica se tornou popular nessas análises pelos corantes empregados (DAPI e mitramicina) por possuírem alta especificidade pelo DNA e alta intensidade de fluorescência. A mitramicina tem um pico de excitação na faixa de 450 a $500 \mathrm{~nm}$. Ambos os corantes possuem fluorescência suficiente para quantificação de DNA cloroplastidial individual, mas somente o DAPI é utilizado para medir partículas individuais de bacteriófago T4 (Coleman et al., 1981). Kubista et al. (1987), em sua revisão, comentaram que o DAPI é muito útil em estudos citoquímicos, como um marcador de DNA na eletroforese, em estudos de interaçôes DNA-proteína, e também proteínas sozinhas, como por exemplo tubulinas.

A cromomicina A (CMA) é um corante definido como um complexo de diversos antibióticos glicosídicos intimamente relacionados derivados do fungo Streptomyces griseus (Biblioteca Virtual em Saúde, 2010). Essas moléculas se ligam em dímeros nos sulcos menores do DNA (GAO;
Patel, 1989). Seu principal componente, a cromomicina $A_{3}$ $\left(\mathrm{CMA}_{3}\right)$, é utilizada como um corante fluorescente de DNA e está registrada sob CAS 7059-24-7. Possui fórmula molecular $\mathrm{C}_{57} \mathrm{H}_{8} \mathrm{O}_{26}$ com peso de 1183,2 (National Center for Biotechnology Information, 2005a) Segundo Schweizer (1976), preparações cromossômicas com o fluorocromo $\mathrm{CMA}_{3}$ produzem padróes de bandamento de acordo com a afinidade de bases do DNA. O corante fluorescente $\mathrm{CMA}_{3}$ se liga às regióes heterocromáticas ricas em bases nitrogenadas guanina e citosina (GC) (GaO; Patel, 1989, Liu; Chen, 1994). Esse fluorocromo pode ser associado a antibióticos como a distamicina, para incrementar o contraste do bandamento, o qual age como um contracorante que se liga às bases nitrogenadas AT, permitindo um maior contraste nas regióes ricas em GC (ZANELA, 2009).

$\mathrm{O} \mathrm{CMA}_{3}$ é um dos fluorocromos mais utilizados em estudos de bandamento, visando à obtenção de padróes diferenciais característicos de bandas fluorescentes nos cromossomos, o que proporciona uma análise mais refinada dos seus conjuntos. Sua fluorescência verde pode ser observada em filtros de excitaçáo de 400 a $440 \mathrm{~nm}$ e de emissão de $475 \mathrm{~nm}$ (Zanela, 2009).

Cabe ressaltar que inúmeros estudos utilizam a combinação de CMA e DAPI em diferentes espécies vegetais, cujas regióes organizadoras do nucléolo e outras partes heterocromáticas são marcadas com CMA, enquanto que as mesmas regiōes se apresentam negativas para DAPI. Essa foi umas das primeiras aplicaçóes dos corantes fluorescentes e, desde entáo, tem se tornado rotina nos laboratórios de citogenética. Do mesmo modo, a utilizaçáo desses fluorocromos permite verificar a ocorrência de processos evolutivos complexos, tais como inversão pericêntrica e duplicação em tandem, em análises tanto em células mitóticas como em células meióticas (Guerra, 1988; Feitoza, 2008).

A fluoresceína é um xanteno, classe de compostos largamente utilizados como corantes. Foi sintetizada pela primeira vez pelo químico alemão Johann Friedrich Adolf von Bayer. Constitui um dos fluorocromos mais comumente usados em citogenética de plantas, apresentando coloração fluorescente amarelo-esverdeada. Está registrada com número CAS 2321-07-5, seu peso molecular é de 332,30 com a fórmula molecular $\mathrm{C}_{20} \mathrm{H}_{12} \mathrm{O}_{5}$ (NATIONAL Center For Biotechnology Information, 2005b). A fluorescência dessa molécula é ativada quando excitada em um comprimento de onda na faixa de 488 a $495 \mathrm{~nm}$ e observada sua emissão numa faixa de 518 a 525 nm (Hermanson, 2008).

Existem diferentes derivados da fluoresceína. Dentre eles, destaca-se o isotiocianato de fluoresceína (FITC). Essa molécula constitui em uma fluoresceína com um grupo funcional isotiocianato $(-\mathrm{N}=\mathrm{C}=\mathrm{S})$ no lugar de um átomo de hidrogênio no anel inferior da estrutura. Esse composto está registrado como CAS 27072-45-3, com fórmula molecular 
$\mathrm{C}_{21} \mathrm{H}_{11} \mathrm{NO}_{5} \mathrm{~S}$ e peso de 389,382. Mantém os mesmos comprimentos de onda de absorção e emissão que a fluoresceína (National Center for Biotechnology Information, 2005c). O grupo isotiocianato é estável, mas em soluçóes aquosas pode degradar em curto período de tempo, sendo, desse modo, recomendado que se use o reagente fresco, e as condiçóes de estoque sejam secas, protegidas da luz em temperaturas abaixo de $-20^{\circ} \mathrm{C}$ (Hermanson, 2008). Essa molécula é amplamente usada na marcação de proteínas, bem como em anticorpos fluorescentes para detecção de patógenos. A NHS-fluoresceína constitui outro derivado aminorreativo e recebe esse nome pela presença de um grupo succinimidil-éster ligado à molécula de fluoresceína (Hermanson, 2008), sendo mais estável para estocagem do que o FITC e possuindo as mesmas características de fluorescência (Hermanson, 2008).

O diacetato de fluoresceína (FDA) detecta a presença de esterases ativas, cuja cor de excitação é azul e a coloração final conferida é verde claro. A principal característica desse fluorocromo é que permite a análise das células-alvo, vivas ou nấo. $\mathrm{O}$ grupo acetil das moléculas de FDA confere a capacidade de penetrar nas membranas celulares, por difusão passiva. Após a entrada das moléculas, as esterases presentes nas células clivam as ligaçóes éster, liberando os grupos acetato e induzindo, desse modo, o brilho típico da fluoresceína, que fica retida no citoplasma. No entanto, em células mortas, como há uma desorganização das membranas, a penetração pelas moléculas de FDA não é seguida pela clivagem das ligaçôes éster que as ligam aos grupos acetato e, portanto, não se verifica o brilho característico da fluoresceína. A molécula de FDA possui peso de 416,39, representada pela fórmula $\mathrm{C}_{24} \mathrm{H}_{16} \mathrm{O}_{7}$ e CAS 596-09-8. Esse fluorocromo é muito utilizado para verificar a viabilidade polínica de diversas espécies (SAHAR; SPIEgEL-Roy, 1984; Cardoso et al., 2004; Sutyemez, 2011).

A rodamina abrange uma família de compostos orgânicos chamados fluoronas. Os corantes do tipo rodamina são usados extensivamente em aplicaçôes biotecnológicas tais como a microscopia de fluorescência, citometria de fluxo e os testes do tipo ELISA (Enzyme Linked Immunosorbent Assay). Há vários derivados de rodamina disponíveis comercialmente para diversos propósitos, alguns aminorreativos são: tetrametilrodamina (dois grupos metil ligados aos átomos de nitrogênio), seu derivado com grupo isotiocianato (TRITC) no lugar de um átomo de hidrogênio no anel inferior da estrutura molecular, rodamina B (dois grupos etil em cada átomo de nitrogênio e um grupo carboxila no anel inferior), NHS-rodamina (molécula base com um grupo funcional éster carboxi-succimidil), sulforodamina $101 \mathrm{e}$ sua forma sulfonilada, também conhecida como Vermelho
Texas, com propriedades luminescentes mais intensas. Além desses, incluem-se como derivados de rodamina as novas fluoronas, tais como Alexa 633, que supre a necessidade de alta fotoestabilidade (Kubin; Fletcher, 1982; Berlier et al., 2003; Lakowicz, 2006; Hermanson, 2008).

Inúmeros são os trabalhos que vêm sendo desenvolvidos a partir do uso de fluoresceínas e rodaminas, além da associaçáo de diversos outros fluorocromos. Dou et al. (2006) realizaram a caracterizaçấo genômica de triticales hexa e octoploides por hibridização genômica in situ (GISH), hibridização in situ fluorescente (FISH), subunidades de gluteninas de alto peso molecular e marcadores de DNA do tipo microssatélites. Do mesmo modo, SePSI et al. (2009) caracterizaram a composição genômica de trigo Thinopyrum ponticum a partir do uso de sondas multicolor visando à análise da introgressão gênica dessa espécie afim ao Triticum aestivum.

Um uso comum para esses dois fluoróforos é a marcação de anticorpos, os quais são usados com frequência em imunoensaios e em microscopia de fluorescência (Lakowicz, 2006). Uma vantagem adicional do uso dessas moléculas constitui-se no espectro de absorçáo e emissão de comprimentos de onda altos, o que possibilita a redução ou ausência da autofluorescência basal de certos componentes celulares que ocorrem em comprimentos de onda mais baixos (FLANAGAN JÚNIOR et al., 1997; LAKowicz, 2006).

Com relação ao emprego conjunto de diferentes fluorocromos e à estratégia de "pinturas cromossômicas", MarKova; Vуsкот (2009) destacaram as aplicaçóes convencionais, recente modificaçôes da técnica de GISH e como as bandas geradas contribuem para a realização dos cariótipos das plantas e de estudos filogenéticos. Um bom par de fluoróforos para contraste de cores em microscopia constitui em corantes de fluoresceína e seus derivados (verde/amarelado) e rodamina e seus derivados (vermelho). Esses últimos, por sua vez, são muito populares por marcarem todos os tipos de biomoléculas. Possuem uma faixa de comprimento de onda de excitaçáo bem variada, de acordo com os átomos presentes em cada derivado. A presença de diferentes grupos nos carbonos 5 ou 6 da molécula base de rodamina também confere diversidade de ligaçôes dos derivados com cada tipo de biomolécula (Hermanson, 2008).

Portanto, resultados obtidos com o uso de corantes fluorescentes têm permitido um melhor entendimento sobre a origem e evolução dos cariótipos de plantas, pelo fato dessas técnicas propiciarem uma comparação entre os padrōes de bandas fluorescentes e sua composição nos diferentes cromossomos e nos diferentes complementos. 


\section{REFERÊNCIAS}

BERLIER, J.E.; ROTHE, A.; BULLER, G.; BRADFORD, J.; GRAY, D.R.; FILANOSKI, B.J.; TELFORD, W.G.; YUE, S.; LIU, J.; CHEUNG, C.; CHANG, W.; HIRSCH, J.D.; BEECHEM, J.M.; HAUGLAND, R.P.; HAUGLAND, R.P. Quantitative comparison of long-wavelength Alexa Fluor dyes to Cy dyes: fluorescence of the dyes and their bioconjugates. Journal of Histochemistry and Cytochemistry, v.51, n. 12, p.1699-1712, 2003.

BIBLIOTECA VIRTUAL EM SAÚDE. Cromomicina A3. In: Descritores das Ciências da Saúde, 2010. Disponível em: <http://decs. bvsalud.org/cgi-bin/wxis 1660.exe/decsserver/?IsisScript=../ cgi-bin/decsserver/decsserver.xis\&search_language=p\&interface language $=$ p\&previous_page=homepage\&task $=$ exact_term\&search_ exp=Cromomicina\%20A3 > . Acesso em: 19 nov. 2010.

BRAMMER, S.P.; ZANOTTO, M.; CAVERZAN, A. Citogenética vegetal: da era clássica à molecular. Passo Fundo: Embrapa Trigo, 2007. 9p. (Embrapa Trigo. Documentos online, 85). Disponível em: <http://www. cnpt.embrapa.br/biblio/do/p_do85.htm>. Acesso em: 23 set. 2010.

BROWN, J.A. H\&E Staining: oversight and insights. In: KUMAR, G.L.; KIERNAN, J.A. (Eds.). Education Guide Special stains and $H$ จ. $E .2^{\text {nd }}$ ed. California: Dako North America, 2010. 300p.

CARDOSO, M.B.; KALTCHUK-SANTOS, E.; MUNDSTOCK, E.C.; BODANESE-ZANETTINI, M.H. Initial segmentation pattern of microspores and pollen viability of soybean cultured anthers: indication of chromosome doubling. Brazilian Archives of Biology and Technology, v.47, n.5, p.703-712, 2004.

COELHO, M.S.E. 2009. Caracterização citogenética de Passiflora edulis f. flavicarpa DEG., P. cincinnata MAST. e seu híbrido interespecífico. 2009. 67f. Dissertação (Mestrado em Agronomia) - Centro de Ciências Agrárias, Universidade Federal da Paraíba, Areia, 2009.

COLEMAN, A.W.; MARK, J.M.; COLEMAN, J.R. Mithramycinand 4'-6-diamidino-2-phenylindole (DAPI)-DNA staining for fluorescence microspectrophotometric measurement of DNA in nuclei, plastid, and virus particles. The Journal of Histochemistry and Cytochemistry, v.9, n.8, p.959-968, 1981.

COUTINHO, A.P. Métodos e Técnicas em Citologia e Fisiologiaalgumas notas sobre diversas técnicas utilizadas nas aulas teórico-práticas - 4a parte. Coimbra: Universidade de Coimbra, FCTUC, 2008.

CRUZ, G.M.G. Glossário de epônimos - nomes que fazem a história da coloproctologia. Revista Brasileira de Coloproctologia, v.29, p.410-419, 2009.

DAPSON, R.W. The history, chemistry and modes of action of carmine and related dyes. Biotechnic and Histochemistry, v.82, n.4-5, p.173-187, 2007.

DOU, Q.W.; TANAKA, H.; NAKATA, N.; TSUJIMOTO, H. Molecular cytogenetic analyses of hexaploid lines spontaneously appearing in octoploid Triticale. Theoretical and Applied Genetics, v. 114 , n. 1, p.41-47, 2006.
EXBRAYT, J.M. Genome visualization by classic methods in light microscopy. New York: CRC Press, 2001. 195p.

FARIA, M. As plantas tintureiras. Oceanos, v.6, p.66-78, 1991.

FEITOZA, L.L. ALISMATALES Sensu strictu: análise citogenética com técnica convencional, bandeamento e sítios de DNAr 45S. 2008. 80f. Dissertação (Mestrado em Botânica) - Universidade Federal Rural de Pernambuco, Recife, 2008.

FLANAGAN JÚNIOR, J.H.; KHAN, S.H.; MENCHEN, S.; SOPER, S.A.; HAMMER, R.P. Functionalized tricarbocyanine dyes as near-infrared fluorescent probes for biomolecules. Bioconjugate Chemestry, v.8, N.5, p.751-756, 1997.

FLEISCHER, B. Editorial: 100 years ago: Giemsa's solution for staining of plasmodia. Tropical Medicine and International Health, v.9, n.7, p.755-756, 2004;

FUJII, M.T.; GUERRA, M. Improved haematoxylin staining for algal cytogenetics. Biotechnic and Histochemistry, v.73, n.2, p.78-81, 1998.

GAO, X.L.; PATEL, D.J. Solution structure of the chromomycinDNA complex. Biochemistry, v.28, n.2, p.751-762, 1989.

GILL, G.W. H\&E Staining: oversight and insights. In: KUMAR, G.L.; KIERNAN, J.A. (Eds.). Education Guide Special stains and $H$ \& E. $2^{\text {nd }}$ ed. California: Dako North America, 2010. 300p.

GUERRA, M. Hematoxylin: a simple, multiple-use dye for chromosome analysis. Genetics and Molecular Biology, v.22, p.77-80, 1988.

GUERRA, M. Introdução a citogenética geral. Rio de Janeiro: Guanabara Koogan, 1998. 142p.

HENDERSON, S.A.; LU, B.C. The uses of haematoxylin for squash preparations of chromosomes. Stain Technology, v.43, p 233-236, 1968.

HERMANSON, G.T. Bioconjugate techniques. $2^{\text {nd }}$ ed. Elsevier, 2008. 1323p.

INVITROGEN. DAPI nucleic acid stain, 2006. Diponível em: <http:// probes.invitrogen.com/media/pis/mp01306.pdf >. Acesso em: 10 mar. 2009.

KAPUSCINSKI J.; YANAGI, K. Selective staining by 4', 6-diamidine2-phenylindole of nanogram quantities of DNA in the presence of RNA on gels. Nucleic Acids Research, v.6, n.11, p.35353542, 1979.

KLERNAN, J.A. H\&E Staining: oversight and insights. In: KUMAR, G.L.; KIERNAN, J.A. (Eds.) Education guide special stains and $H \odot$ E. $2^{\text {nd }}$ ed. California: Dako North America, 2010. 300p.

KUBIN, R.F.; FLETCHER, A.N. Fluorescence quantum yields of some rhodamine dyes. Journal of Luminescence, v.27, p.455-462, 1982. 
KUBISTA, M.; AKERMAN, B.; NORDÉN, B. Characterization of interaction between DNA and 4'-6-diamidino-2-phenylindole by optical spectroscopy. Biochemistry, v.26, p.4545-4553, 1987.

LAKOWICZ, J.R. Principles of fluorescence spectroscopy. $3^{\text {rd }}$ ed. Sigapure: Springer, 2006. 954p.

LIU, C., CHEN, F-M. Oligonucleotide studies of sequence-specific binding of chromomycin $A_{3}$ to DNA. Biochemistry, v.33, n.6, p.1419-1424, 1994.

MARKOVA, M.; VYSKOT, B. New horizons of genomic in situ hybridization. Cytogenetic and Genome Research, v.126, n.4, p.368-375, 2009.

MENDEZ, T.M.; PINHEIRO, A.L.; PACHECO, M.T.; NASCIMENTO, P.M.; RAMALHO, L.M. Dose and wavelength of laser light have influence on the repair of cutaneous wounds. Journal of Clinical Laser Medicine and Surgery, v.22, n. 1, p. 19-25, 2004.

NATIONAL CENTER FOR BIOTECHNOLOGY INFORMATION. PubChem BioAssay Database. Chromomycin A3. CID 656673. 2005a. Disponível em: <http://pubchem.ncbi.nlm.nih.gov/ summary/summary.cgi? cid $=656673>$. Acesso em: 12 jun. 2011.

NATIONAL CENTER FOR BIOTECHNOLOGY INFORMATION. PubChem BioAssay Database. Fluorescein. CID 16850. 2005b. Disponível em: <http://pubchem.ncbi.nlm.nih.gov/summary/ summary.cgi?cid=16850>. Acesso em: 12 jun. 2011.

NATIONAL CENTER FOR BIOTECHNOLOGY INFORMATION. PubChem BioAssay Database. Fluorescein-5-isothiocyanate. CID 18730. 2005c. Disponível em: http://pubchem.ncbi.nlm.nih.gov/ summary/summary.cgi?cid=18730. Acesso em: 12 jun. 2011 .

OTTO, F.J. High-resolution analysis of nuclear DNA emplying the fluorochrome DAPI. Methods in Cell Biology, v.41, p.211217, 1994.

SAHAR, N.; SPIEGEL-ROY, P. In vitro germination of avocado pollen. HortScience, v. 19, n.6, p.886-888, 1984.

SAXENA, R. H\&E Staining: oversight and insights. In: KUMAR, G.L.; KIERNAN, J.A. (Eds.) Education Guide Special stains and $H \odot$ E. $2^{\text {nd }}$ ed. California: Dako North America, 2010. 300p.

SCHWEIZER, D. Reverse fluorescent chromosome-banding with Chromomycin A and DAPI. Chromosoma, v.58, n.4, p.307-324, 1976.

SHU, D.; YU-KYOUNG, O.; CHAIRES, J.B. Determining mode of DNA sequence specific compounds. Process Biochemistry, v. 37, n.5, p.521-525, 2001;
SEPSI, A.; MOLNÁR, I.; MOLNÁR-LÁNG, M. Physical mapping of a 7A.7D translocation in the wheat-Thinopyrum ponticum partial amphiploid BE-1 using multicolour genomic in situ hybridization and microsatellite marker analysis. Genome, v.52, n.9, p.748-754, 2009.

SIGMA-ALDRICH. DAPI 4',6-Diamidino-2-phenylindole, 2008. St. Louis: Sigma-Aldrich, 2009. Disponível em: <http://www. sigmaaldrich.com/etc/medialib/docs/Sigma/Product_Information_ Sheet/d8417pis.Par.0001.File.tmp/d8417pis.pdf>. Acesso em: 10 mar. 2009.

SIGMA-ALDRICH. Solução de hematoxilina de Harris Accustain Procedimento No HHS. Egham: AR-MED Ltd., 2003. Disponível em: <http://www.sigmaaldrich.com/etc/medialib/docs/Sigma/ General_Information/1/insert_pt_hhs.Par.0001.File.tmp/insert_ pt_hhs.pdf>. Acesso em: 20 jul. 2010.

SUTYEMEZ, M. Pollen quality, quantity and fruit set of some selfcompatible and self-incompatible cherry cultivars with artificial pollination. African Journal of Biotechnology, v.10, n. 17, p.33803386, 2011.

TANIOUS, F.A.; VEAL, J.M.; BUCZAK, H.; RATMEYER, L.S.; WILSON, W.D. DAPI (4',6-diamidino-2-phenylindole) binds differently to DNA and RNA: minor-groove binding at AT sites and intercalation at AU sites. Biochemistry, v.31, n.12, p.3101-3112, 1992.

TAYLOR, I.W. A rapid single step staining technique for DNA analysis by flow microfluorimetry. The Journal of Histochemistry and Cytochemistry, v.28, n.9, p.1021-1024, 1980.

THERMO SCIENTIFIC. DAPI Nuclear Counterstain: a blue nuclear counterstain for fluorescence microscopy and cellular imaging. Rockford: Thermo Fisher Scientific Inc., 2009. Disponível em: <http://www.piercenet.com/Products/Browse.cfm?fldID $=010$ $41204 \&$ CFID $=5811641 \&$ CFTOKEN $=22379885>$. Acesso em: 07 jul. 2010.

TITFORD, M. The long history of hematoxylin. Biotechnic $\odot$ Histochemystry, v.80, n.2, p.73-78, 2005.

TROCONÍS, J.G.P. El añil: historia de un cultivo olvidado en Venezuela 1767-1870. 2000. 102f. Tese (Doutorado em Econômica) Universidad Autonoma de Barcelona, Barcelona, 2000.

WITTMANN, W. Aceto-iron-haematoxylin-chloral hydrate for chromosome staining. Biotechnic $\odot$ Histochemistry, v.40, n.3, p.161-164, 1965.

ZANELA, L. Caracterização cariotípica de quatro espécies brasileiras de Alstroemeria (Alstroemeriaceae) com as técnicas de FISH, CMA, DAPIE AgNOR. 2009. 96f. Dissertação (Mestrado em Agricultura Tropical e Subtropical) — Instituto Agronômico de Campinas, Campinas, 2009. 